\title{
REVIEW OF THE USE OF MESOPOROUS SILICAS FOR REMOVING DYE FROM TEXTILE WASTEWATER
}

\author{
ZEINAB SALAHSHOOR and AFSANEH SHAHBAZI*
}

Environmental Sciences Research Institute, Shahid Beheshti University, G.C., Tehran 1983963113, Iran
* Corresponding author: a_shahbazi@sbu.ac.ir

\section{ABSTRACT}

The textile industry is a major user of dyes and hence an important source of water pollution, which poses a threat to aquatic as well as human life. Adsorption is a widely used technique for separating and removing dye from wastewater. Recently the use of mesoporous silica (MPSs) as an adsorbent in wastewater treatment has received considerable attention. MPSs are emerging as potential adsorbents because of their surface area, tunable and uniform pore structure, high pore volume, ordered pore structure, thermal and mechanical stability, and extraordinarily wide possibilities for functionalization to increase their adsorption capacity. In this paper the ability of MPSs to absorb dyes from aqueous solutions is reviewed. This article provides information on adsorption studies carried out under different operational conditions such as contact time, solution $\mathrm{pH}$, temperature, agitation speed, etc. This review also summarizes and attempts to compare the equilibrium isotherm and kinetic models, and the thermodynamic studies that report the adsorption of dyes onto MPSs. The literature reviewed, indicate that SBA-MPSs have a higher adsorption capacity than MCM-MPSs and functionalized MPSs a better adsorption capacity than MPSs. It is evident from the literature that the potential of MPS based nano-sorbents being used for removing dyes from aqueous solution is very high. However, still more research work is needed on developing cost effective and more efficient MPS based nano-sorbents for use commercially.

Keywords: nano-sorbent, functionalization, adsorption, isotherm, kinetic

\section{Introduction}

The treatment of industrial wastewater has become more important in recent years as industrial effluents contain many toxic pollutants, such as dyes, which can severely damage the environment (Ho et al. 2000; Huang et al. 2011b). There are over 100,000 commercially available dyes. The total worldwide consumption of dyes by the textile industries is in excess of $10^{7} \mathrm{~kg}$ per year, and approximately one million kilograms of dye are discharged into rivers and streams by textile industries each year (Órfão et al. 2006; Demirbas 2009; Huang et al. 2011b). The major problem associated with the discharge of large quantities of these organic compounds in wastewater is their chemical stability and low biodegradability in water due to their complex aromatic structure and synthetic origin, which is potentially harmful to the environment. Also many of them are known to be toxic or carcinogenic (Crini and Badot 2008; Fatimah et al. 2011). Various physical, chemical and biological techniques, such as ultrafiltration, reverse osmosis, ion exchange and adsorption on various adsorbents have been developed for removing dye from aqueous solutions (Huang et al. 2011a). Chemical techniques are often expensive and the accumulation of concentrated sludge from which dye has been removed presents a disposal problem. In addition, a secondary pollution problem may arise due to the excessive use of chemicals (Karim et al. 2012). Adsorption is one of the most attractive technologies because it is highly efficient, cheap and easy to use (Debnath et al. 2013). The key aspect of adsorption technology is an excellent adsorbent with high adsorption capacity, rapid adsorption kinetics as well as high selectivity for adsorbates during the adsorption process. Various traditional adsorbents, such as zeolite, clay, activated carbon, fly ash, peat, microbial biomass and agricultural residues have been used for removing dye from wastewater. Inherent disadvantages of these materials are their low loading capacities, relatively small dye binding constants and poor selectivity (Zhuang et al. 2009; Huang et al. 2011a; Debnath et al. 2013).

Over the past two decades, mesoporous silica (MPS) such as SBA-15, MCM-41, SBA-3 and MCM-48 have received extensive attention as promising adsorbents with a wide field of applications due to their high surface area, tunable and uniform pore structure, high pore volume, ordered pore structure, thermal and mechanical stability and extraordinarily wide possibilities for functionalization (Yan et al. 2006a; Chen et al. 2012). In recent years, MPSs have been used to adsorb heavy metal ions (Aguado et al. 2009; Li et al. 2011; Addy et al. 2012; Shahbazi et al. 2013; Shahbazi et al. 2014), organic dyes (Pugazhenthi 2009; Qin et al. 2009; Huang et al. 2011a; Huang et al. 2011b; Boukoussa et al. 2013; Badiei et al. 2014), polycyclic aromatic hydrocarbons (Choudhary and Mantri 2000; Dou et al. 2011; Vidal et al. 2011; Balati et al. 2014) and other organic pollutants and the results indicate that the MPSs have excellent adsorption ability (Kim et al. 2011; Najafi et al. 2012). There are a few studies on the use of MPSs for adsorbing dyes, mainly because MPSs were first synthesized in the early 1990s. In addition, these materials have rarely been used for treating wastewater. 
Table 1 Chemical structure of typical textile dyes.

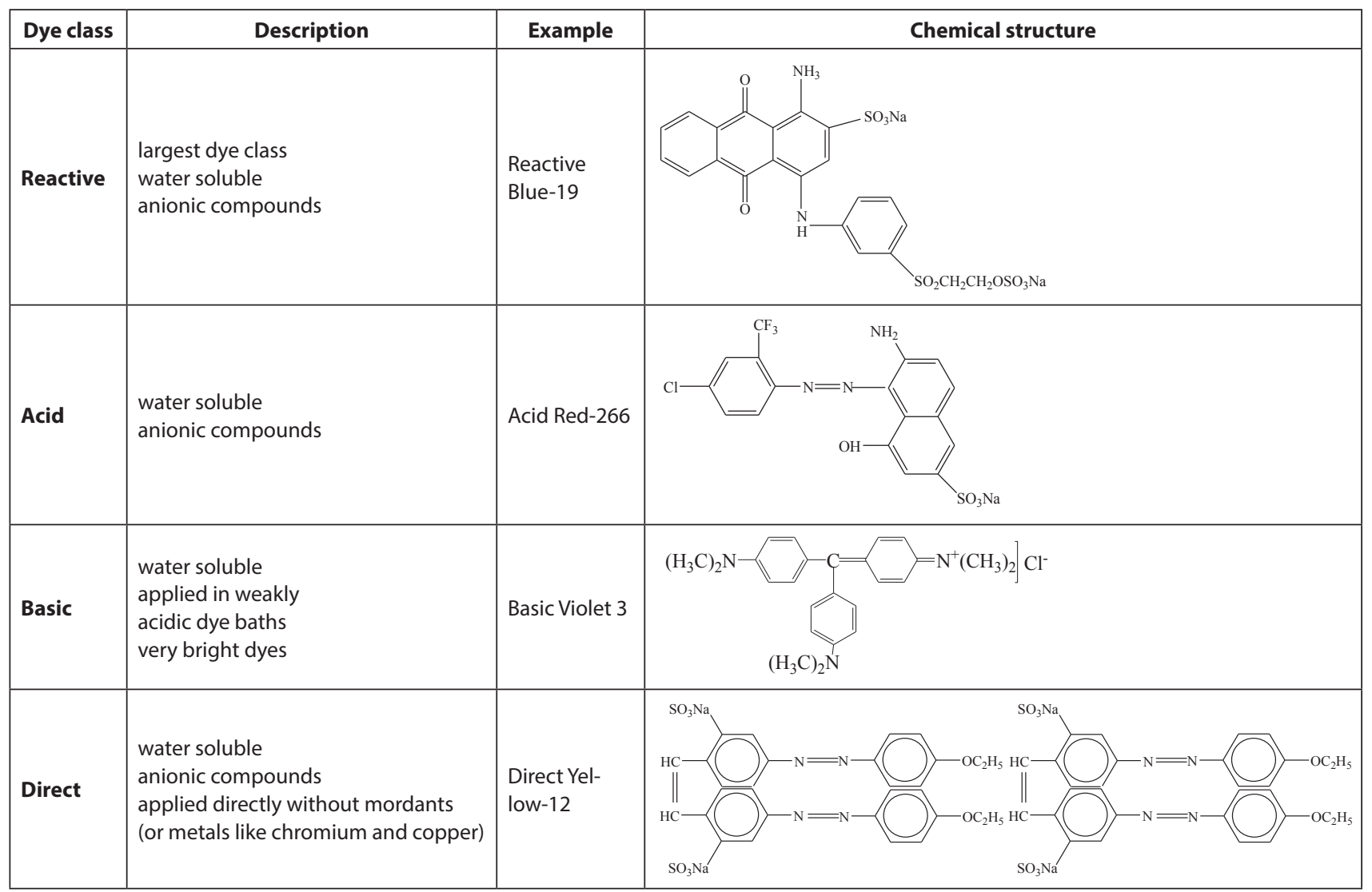

In this paper, the data on the use of various MPSs for adsorbing dyes is reviewed. The effects of various parameters, such as the process variables and experimental conditions are presented and discussed. The equilibrium and kinetic models which are used to characterize the adsorption processes are also reviewed.

\section{Classification of textile dyes}

Dyes are normally water-soluble or water dispersible organic compounds that are capable of being absorbed into a substrate (Kulkarni and Ruppersberger 1985). In dye molecules there are two important components: the chromophore, which is responsible for producing the colour and auxochromes, which are ionizable groups that enhance the affinity of the dye for fibers (Demirbas 2009; Salleh et al. 2011). The chromophore configurations are the azo group $(-\mathrm{N}=\mathrm{N}-)$, ethylene group $(=\mathrm{C}=\mathrm{C}=)$, methine group $(-\mathrm{CH}=)$, carbonyl group $(=\mathrm{C}=\mathrm{O})$, carbon-nitrogen $(=\mathrm{C}=\mathrm{NH} ;-\mathrm{CH}=\mathrm{N}-)$, carbon-sulphur $(=\mathrm{C}=\mathrm{S}$; $\equiv \mathrm{C}-\mathrm{S}-\mathrm{S}-\mathrm{C} \equiv)$, nitro $\left(-\mathrm{NO}_{2} ;-\mathrm{NO}-\mathrm{OH}\right)$ and nitrozo $(-\mathrm{N}=\mathrm{O} ;=\mathrm{N}-\mathrm{OH})$. The common auxochrome groups are: amino $\left(-\mathrm{NH}_{2}\right)$, carboxyl $(-\mathrm{COOH})$, sulphonate $\left(-\mathrm{SO}_{3} \mathrm{H}\right)$ and hydroxyl (-OH) (Rai et al. 2005; Herbst and Hunger 2007; Carmen and Daniela 2012).

The nature and origin of dye are the criteria used in the general classification of natural and synthetic textile dyes (Carmen and Daniela 2012). Dyes also can be classified with regard to their chemical structure (e.g. azo, anthraquinone, indigo, triphenylmethane), the method and domain of usage (e.g. direct, reactive, chromic, metal-complexes, disperse, mordant, sulphur, vat, pigments), and/or their chromogen (e.g. donor-acceptor, cyanine, polyenes) (Kulkarni and Ruppersberger 1985; Herbst and Hunger 2007; Demirbas 2009).

Considering only their general structure, textile dyes are also classified into anionic, nonionic and cationic dyes (Rajeshwar et al. 2008; Demirbas 2009; Salleh et al. 2011). Anionic dyes are direct, acid and reactive. The release of a water soluble reactive into the environment is undesirable because they have a low degree of fixation due to the hydrolysis of reactive groups in the water phase (Shreve and Watson 1922; Laing et al. 1991; Salleh et al. 2011). Nonionic dyes are dispersive dyes because they do not ionize in an aqueous medium (Robinson et al. 2001; Dos Santos et al. 2007). Cationic (basic) dyes have different chemical structures based on substituted aromatic groups (Limaye and Ruparelia 2011; Salleh et al. 2011). Principal chemical classes are diazahemicyanine, triarylmethane, cyanine, hemicyanine, thiazine, oxazine and acridine. Some basic dyes are biologically active and used in medicine as antiseptics (Hunger 2002). Cationic groups of dyes are toxic colorants and can have harmful effects, such as allergic dermatitis, skin irritation, mutations and cancer (Vigo 1994; Salleh et al. 2011). 
As mentioned, there are many structural varieties, such as acidic, dispersive, basic, azo, diazo, anthraquinone-based and metal complex dyes. Azo and anthraquinone colorants are the two major classes of synthetic dyes and pigments. Together they represent about $90 \%$ of all organic colorants (Kulkarni and Ruppersberger 1985; Demirbas 2009; Salleh et al. 2011). Depending on pH, the azo dyes can be anionic (deprotonation at the acidic group), cationic (protonated at the amino group) or nonionic. Accordingly, knowledge of the $\mathrm{pH}$ is indispensable for characterizing the behaviour of azo dyes (Lallas 2001; Lichtfouse 2005; Gregory 2009; Carmen and Daniela 2012). Some examples of common textile dyes are presented in Table 1.

\section{Methods of treatment for removing dyes}

The textile industry is one of the greatest generators of liquid effluent pollutants, due to the high quantities of water used in dyeing processes (Banat et al. 1996; Saratale et al. 2011). Several methods are used for removing dye from wastewater. Technologies can be divided into three categories: biological, chemical and physical (Robinson et al. 2001; Crini 2006; Demirbas 2009).

Biological treatment is often the most economical alternative to physical and chemical processes (Crini 2006; Saratale et al. 2011). However, application of biological treatment is often restricted because of technical constraints. Biological treatment requires a large land area and is constrained by diurnal variation and toxicity of some chemicals and the inflexibility of the design and operation (Crini 2006; Martínez-Huitle and Brillas 2009).

The most important disadvantage of chemical methods is the production of sludge resulting from the use of chemicals and in addition, the disposal of the sludge is expensive. There is also the possibility that a secondary pollution problem will arise because of the excessive use of chemicals (Slokar and Majcen Le Marechal 1998; Robinson et al. 2001; Demirbas 2009; Huang et al. 2011a). Adsorption is globally recognized as the most promising method of wastewater treatment because of its versatility, wide applicability and low cost (Demirbas 2009; Weng et al. 2009; Eftekhari et al. 2010; Huang et al. 2011b). Most adsorbents are easily available and inexpensive. However, their practical application has been limited by problems associated with their regeneration, disposal, poor mechanical stability, high sludge production and low removal effectiveness of a wide range of dyes (Crini 2006; Yang and Feng 2010a; Saratale et al. 2011; Nguyen and Juang 2013). To overcome these disadvantages, which are a major challenge for dye treatment, various nano-adsorbents have been developed. After 1995, some attempts were made to prepare and use these nano-sized materials to simply remove dyes from aqueous systems. An early attempt was that of $\mathrm{Wu}$ and co-workers, who adsorbed several anionic dyes on nano-sized alumi- na-modified silica particles of different compositions (Wu et al. 1997). Among nano-adsorbents, nanostructure materials such as MPSs have been found to be suitable adsorbents for the removal of dyes from wastewater (Joo et al. 2009; Anbia and Hariri 2010; Anbia and Salehi 2012). MPSs offer significant improvements over conventional adsorbents with their extremely high specific surface area, short intraparticle diffusion distance, tunable pore size, changeable surface chemistry and high adsorption capacity (Zhang 2007; Vimonses 2011; Qu et al. 2012; Qu 2013).

\section{Dye adsorption by mesoporous silicas}

Since 1992 MPSs have been commonly used as adsorbents (Paul et al. 2012). They are of interest because of their relatively large pores, which facilitate mass transfer, the very high surface area, which allows a high concentration of active sites per mass of dye and high mechanical stability (Tsoncheva et al. 2007; Yang and Feng 2010b; Tseng et al. 2012). In addition, it is possible to change their surface chemistry by anchoring various chemical functional groups onto pore walls, which are exceptionally selective and have a high capacity for adsorbing various dyes (Liu et al. 1998; Taguchi and Schüth 2005; Chew et al. 2010; Yang and Feng 2010a; Huang et al. 2011b; Karim et al. 2012). The three consecutive steps in the adsorption of dye by MPSs adsorbent are:

(i) Transport of the dye to the external surface of the adsorbent (film diffusion).

(ii) Transport of the dye within pores of the adsorbent, only a small amount of the dye is adsorbed on the external surface (particle diffusion).

(iii) Adsorption of the dye on an inner surface of the adsorbent (Mohan and Singh 2002; Ping Ge 2011).

The adsorption efficiency of various MPSs of some dyes is summarized in Table 2. According to the literature (Table 2), SBA-15 has a significantly higher adsorption capacity than MCM-48 due to its larger pore size $(5.27 \mathrm{~nm}$ vs. $3.0 \mathrm{~nm})$, which allows dye molecules to easily diffuse from surface to pores of SBA-15 (Wang and Li 2006; Juang et al. 2007; Huang et al. 2011b). In addition, the adsorption capacity and efficiency of MPSs depends on the functional group and class of dye. It is well-known that MPSs have a negative surface charge due to the presence of $\mathrm{Si}-\mathrm{OH}$ groups, which promotes the adsorption of positively charged dyes. Therefore, the effectiveness of MPSs in the adsorption processes is highly dependent on the functionalization of the surface of the silica network with functional groups that are suitable for adsorption of specific substances. a variety of surface functionalized mesoporous silicas have been used for adsorbing varies dyes (Table 2). For example, the adsorption of cationic dye by chitosan-functionalized MPS is $0.012 \mathrm{mmol} / \mathrm{g}$ and that of anionic dye by amino-functionalized MPS 0.6-1.96 mmol/g (Cestari et al. 2007; Zu- 
Table 2 Adsorption of various dyes by MPSs and their functionalized derivatives.

\begin{tabular}{|c|c|c|c|c|c|c|c|c|}
\hline \multicolumn{4}{|c|}{ Mesoporous silica } & \multicolumn{2}{|r|}{ Dye } & \multicolumn{2}{|c|}{$\begin{array}{l}\text { Removal } \\
\text { efficiency }\end{array}$} & \multirow[b]{2}{*}{ Ref. } \\
\hline Type & $\begin{array}{l}\text { Surface } \\
\text { area } \\
\left(\mathrm{m}^{2} / \mathrm{g}\right)\end{array}$ & $\begin{array}{l}\text { Pore } \\
\text { size } \\
(\mathrm{nm})\end{array}$ & Functional group & Class & Name (abbreviation) & $\mathbf{R} \%$ & $\begin{array}{c}Q_{e} \\
(\mathrm{mmol} / \mathrm{g})\end{array}$ & \\
\hline \multirow{8}{*}{ MCM } & 1647 & 3.8 & - & \multirow{6}{*}{ Cationic } & Methylene Blue (MB) & - & \multirow{3}{*}{$\begin{array}{l}0.14 \\
0.04 \\
0.07\end{array}$} & (Wang and Li 2006) \\
\hline & 1149 & 3.0 & - & & Methylene Blue (MB) & - & & (Wang and Li 2006) \\
\hline & 1222 & 5.6 & - & & Methylene Blue (MB) & - & & (Wang and Li 2006) \\
\hline & 754 & 2.55 & Carboxylic & & Methylene Blue (MB) & - & 0.3 & (Ho et al. 2003) \\
\hline & 1003 & - & - & & Basic Violet 10 (BV-10) & - & 1.04 & (Juang et al. 2006) \\
\hline & 1448 & - & $\mathrm{Al}$ & & Yellow Dye (YD) & 92.0 & - & (Boukoussa et al. 2013) \\
\hline & 774 & 2.5 & $\mathrm{NH}_{2}$ & . & Acid Blue 25 (AB-25) & - & 0.6 & (Ho et al. 2003) \\
\hline & 215 & 1.8 & $\mathrm{NH}_{2}$ & 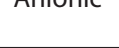 & Remazol Red & 99.1 & - & (Santos et al. 2013) \\
\hline \multirow{12}{*}{ SBA } & 659 & 5.2 & - & \multirow{5}{*}{ Cationic } & \multirow{2}{*}{$\begin{array}{l}\text { Janus Green B (JGB) } \\
\text { Methylene Blue (MB) }\end{array}$} & \multirow{2}{*}{$\begin{array}{c}- \\
99.1\end{array}$} & \multirow{2}{*}{$\begin{array}{l}0.13 \\
0.15\end{array}$} & (Huang et al. 2011b) \\
\hline & 659 & 5.2 & - & & & & & (Huang et al. 2011b) \\
\hline & 707 & 1.9 & Hyperbranchedpolyglycerol & & Methylene Blue (MB) & - & $<0.5$ & (Chen et al. 2012) \\
\hline & \multirow{2}{*}{768} & \multirow{2}{*}{8.9} & \multirow{2}{*}{-} & & \multirow{2}{*}{$\begin{array}{l}\text { Safranine T (ST) } \\
\text { Malachite green (MG) }\end{array}$} & \multirow{2}{*}{$\begin{array}{l}83.6 \\
95.7\end{array}$} & - & (Paul et al. 2012) \\
\hline & & & & & & & - & (Paul et al. 2012) \\
\hline & 1005 & 21.6 & \multirow{4}{*}{$\begin{array}{l}\text { Ethylenediamine } \\
\text { Aminopropyl } \\
\text { penta ethylene hexamine }\end{array}$} & \multirow{7}{*}{ Anionic } & Acid Blue 113 & 83.6 & - & (Anbia and Salehi 2012) \\
\hline & 1435 & 19.2 & & & Acid Red 114 & 85.5 & - & (Anbia and Salehi 2012) \\
\hline & 1290 & 16.8 & & & Acid Green 28 & 95.9 & - & (Anbia and Salehi 2012) \\
\hline & 1092 & 16.3 & & & Acid Yellow 127 & 88.2 & - & (Anbia and Salehi 2012) \\
\hline & 1435 & - & - & & \multirow{3}{*}{$\begin{array}{l}\text { Methyl Orange(MO) } \\
\text { Orange G (OG) } \\
\text { Brilliant Red X-3 B (X3B) }\end{array}$} & \multirow{3}{*}{$\begin{array}{l}82.0 \\
79.0 \\
60.0\end{array}$} & \multirow{3}{*}{$\begin{array}{l}0.52 \\
0.35 \\
0.18\end{array}$} & (Anbia et al. 2010) \\
\hline & 1435 & - & - & & & & & (Anbia et al. 2010) \\
\hline & 1435 & - & - & & & & & (Anbia et al. 2010) \\
\hline \multirow{8}{*}{ MPS } & 285 & 19.0 & \multirow{2}{*}{ Dimethyldecylamine } & \multirow{7}{*}{ Anionic } & \multirow{2}{*}{$\begin{array}{l}\text { Dark Yellow GG } \\
\text { Red Violet X-2R }\end{array}$} & - & \multirow{2}{*}{$\begin{array}{l}1.71 \\
0.90\end{array}$} & (Yang and Feng 2010a) \\
\hline & 285 & 19.0 & & & & - & & (Yang and Feng 2010b) \\
\hline & 313 & - & $\mathrm{NH}_{2}$ & & Acid Red 14 (AR-14) & 75.0 & - & (Mahmoodi et al. 2011) \\
\hline & 313 & - & $\mathrm{NH}_{2}$ & & Acid Black 1 (AB-1) & 83.0 & - & (Mahmoodi et al. 2011) \\
\hline & 313 & - & $\mathrm{NH}_{2}$ & & Acid Blue 25 (AB-25) & 78.0 & - & (Mahmoodi et al. 2011) \\
\hline & 516 & 4.6 & Dimethyldecylamine & & Yellow GG(YGG) & - & 1.96 & (Yang and Feng 2010b) \\
\hline & 516 & 4.6 & Dimethyldecylamine & & Red Violet X-2R & - & 0.96 & (Yang and Feng 2010b) \\
\hline & 906 & 11.2 & Carboxylic & Cationic & Methylene Blue (MB) & & - & (Chang et al 2013b) \\
\hline
\end{tabular}

bieta et al. 2008; Cestari et al. 2009). MPSs functionalized with carboxylic and amino groups have been fabricated for capturing basic and acidic dyes, respectively, are very efficient (good selectivity, large capacity and extremely rapid adsorption rate) because of the designed strong electrostatic interactions and their high surface areas (Ho et al. 2003; Anbia and Salehi 2012; Santos et al. 2013). Also both the adsorbent and dye can be easily recovered by simply washing with an alkaline or acid solution. Without surface modification, surfactants such as MPPSs are essential for removing dyes (Anbia et al. 2010; Santos et al. 2013). The greater selective adsorption of anionic dyes from an aqueous solution by $\mathrm{PDDA}^{1}$ functionalized SBA-15 is due to its larger adsorption capacity than that

1 Polydiallyldimethylammonium chloride. of PDDA functionalized commercial silica and granular activated carbon $(360 \mathrm{mg} / \mathrm{g}$ vs. 40.8 and $29.6 \mathrm{mg} / \mathrm{g}$, respectively). This is due to its relatively large surface area and pore diameters in the mesopore range. It is concluded that pore structure and the superior properties of the MPSs affect the impregnation of PDDA, which results in a high PDDA loading and adsorption performance (Ho et al. 2003; Joo et al. 2009). The desorption of Remazol Red dye by $\mathrm{NH}_{2}-\mathrm{MCM}-41$ is highly efficient $(98.2 \%)$ and greater than that obtained using $\mathrm{Fe}(\mathrm{III}) / \mathrm{Cr}$ (III) hydroxide $(9 \%)$ and several carbon-based adsorbents (Ho et al. 2003; Santos et al. 2013). MPSs are easily protonated in water, which results in their having a charged surface that interacts with other ions in solution. Therefore, MPS could be used as efficient adsorbents for the removal of dye (Walcarius and Mercier 2010). 


\section{Synthesis and functionalization of MPSs}

Typically, MPSs synthesize tunable pore sizes and geometry in the presence of different cationic/anionic surfactants, which act as templates (Norhasyimi Rahmat 2010; Alothman 2012; Pal and Bhaumik 2013). MPSs of various structures, such as hexagonal, cubic and lamellar form are formed by varying the type of surfactant and surfactant/silica ratio. For example, MCM-41 prepared using cationic cetyltrimethylammonium (CTA) surfactants, after calcination yield a hexagonally ordered porous solid with uniform pore sizes of 20 to $30 \AA$ (Ying et al. 1999; Ogawa 2002; Øye et al. 2006). There are various physical and covalent strategies for functionalizing MPSs, such as co-condensation (one-pot synthesis), grafting (post-synthesis modification) and imprint coating (Vinu 2005; Slowing et al. 2008; Zhao et al. 2012). Co-condensation of a tetraalkoxysilane and one or more orgaoalkoxysilanes has been widely used for producing inorganic-organic hybrid networks. The advantages of this method are: (i) applicable to a wide variety of organoalkoxysilanes; (ii) suitable for a wide range of reaction conditions; (iii) the coverage of functional groups is homogeneous; (iv) the functional groups can be heavily loaded without dramatically affecting the structural ordering of the pores (Slowing et al. 2008; Yokoi et al. 2012). Post-grafting was the first method used to modify MPSs. Basically, this method involves a reaction between an organosilane and silanol group using a solvent under reflux conditions to form covalent attachment of func- tional groups to the surface of the material. Among the disadvantages of this method is the reduction in pore size and pore volume caused by the attachment of the functional group (Huang 2009; Norhasyimi Rahmat 2010; Pal and Bhaumik 2013).

The third type is periodic mesoporous organosilic form of the ion method, i.e., bridging organic units are directly incorporated in the three-dimensional network structure of the silica matrix (Hoffmann et al. 2006; Pal and Bhaumik 2013).

\section{Effect of adsorption factors on dye removal}

\section{Effect of $\mathrm{pH}$}

The $\mathrm{pH}$ of the solution has a marked effect on the adsorption process, especially of dyes. This has been studied by preparing an adsorbent-adsorbate solution with defined adsorbent dose and dye concentration and adjusting the $\mathrm{pH}$ using $\mathrm{NaOH}(1 \mathrm{M})$ or $\mathrm{HCl}(1 \mathrm{M})$. In fact, $\mathrm{pH}$ can affect the structural stability of dyes and therefore the intensity of the colour (e.g. transforming a dye to a leuco-structure under alkaline conditions (Badiei et al. 2014)). Hence, the selection of the range in $\mathrm{pH}$ to be used in studies on dye adsorption is a key point. The effect of $\mathrm{pH}$ on the adsorption of organic dyes using MPSs is summarized in Table 3.

The $\mathrm{pH}$ will control the magnitude of the electrostatic charges imparted by the ionized dye molecules. As a result the adsorption efficiency will vary with the $\mathrm{pH}$ of an

Table 3 The effect of $\mathrm{pH}$ on the adsorption of organic dyes by MPSs.

\begin{tabular}{|c|c|c|c|c|c|c|c|}
\hline \multirow{2}{*}{$\begin{array}{c}\text { Mesoporous silica } \\
\text { Type }\end{array}$} & \multicolumn{2}{|c|}{ pH } & \multicolumn{2}{|r|}{ Dye } & \multicolumn{2}{|c|}{ Removal efficiency } & \multirow{2}{*}{ Ref. } \\
\hline & Rang of pH & Optimum pH & Class & Name (abbreviate) & $Q_{e}(\mathrm{mmol} / \mathrm{g})$ & $\mathbf{R} \%$ & \\
\hline \multirow{12}{*}{ MCM } & $2-11$ & 6 & \multirow{7}{*}{ Cationic } & Basic Violet 10(BV10) & 0.75 & - & (Juang et al. 2007) \\
\hline & $2-11$ & 11 & & Crystal Violet(CV) & 0.34 & 98 & (Monash and Pugazhenthi 2009) \\
\hline & $2-12$ & 7 & & Methylene Blue(MB) & 0.21 & 94 & (Eftekhari et al. 2010) \\
\hline & $2-12$ & 7 & & Rhodamine $\mathrm{B}(\mathrm{RB})$ & 0.09 & 79 & (Eftekhari et al. 2010) \\
\hline & $2-11$ & 8 & & Rhodamine $B(R B)$ & 0.80 & - & (Lee et al. 2007) \\
\hline & $2-11$ & 8 & & Crystal Violet (CV) & 0.50 & - & (Lee et al. 2007) \\
\hline & $2-11$ & 8 & & Methylene Green(MG) & 0.25 & - & (Lee et al. 2007) \\
\hline & $4-11$ & 4 & \multirow{5}{*}{ Anionic } & Methyl Orange(MO) & 1.12 & - & (Qin et al. 2009) \\
\hline & $4-11$ & 4 & & Orange Iv (OIV) & 1.09 & - & (Qin et al. 2009) \\
\hline & $4-11$ & 4 & & Reactive Brilliant(RB) & 0.43 & - & (Qin et al. 2009) \\
\hline & $4-11$ & 4 & & Acid Fuchsine(AF) & 0.34 & - & (Qin et al. 2009) \\
\hline & $4-11$ & 4 & & Red $X-3 B(X-3 B)$ & 0.45 & - & (Qin et al. 2009) \\
\hline \multirow{5}{*}{ MPS } & 2 & 2 & \multirow{5}{*}{ Anionic } & Dark Yellow GG & 1.71 & - & (Yang and Feng 2010a) \\
\hline & 2 & 2 & & Red Violet X-2R & 0.90 & - & (Yang and Feng 2010a) \\
\hline & $2-10$ & 2 & & \multirow{3}{*}{$\begin{array}{l}\text { Acid Red 14(AR14) } \\
\text { Acid Black 1(AB1) } \\
\text { Acid Blue 25(AB25) }\end{array}$} & - & 80 & (Mahmoodi et al. 2011) \\
\hline & $2-10$ & 2 & & & - & 78 & (Mahmoodi et al. 2011) \\
\hline & $2-10$ & 2 & & & - & 75 & (Mahmoodi et al. 2011) \\
\hline \multirow{2}{*}{ SBA } & $2-12$ & 8 & \multirow{2}{*}{ Cationic } & Methylene Blue(MB) & 0.880 & 99 & (Dong et al. 2011) \\
\hline & $4-12$ & 8 & & Methylene Blue(MB) & 0.875 & - & (Anbia and Hariri 2010) \\
\hline
\end{tabular}


Table 4 The effect of adsorbent dosage on the adsorption of dyes by MPSs.

\begin{tabular}{|c|c|c|c|c|c|c|c|}
\hline \multirow{2}{*}{$\begin{array}{c}\begin{array}{c}\text { Mesoporous } \\
\text { silica }\end{array} \\
\text { Type }\end{array}$} & \multicolumn{2}{|r|}{ Dye } & \multicolumn{2}{|c|}{ Experimental condition } & \multicolumn{2}{|c|}{ Removal efficiency } & \multirow{2}{*}{ Ref. } \\
\hline & Class & Name (abbreviate) & $\begin{array}{l}\text { Dye concentration } \\
(\mathrm{mg} / \mathrm{l})\end{array}$ & $\begin{array}{c}\text { Adsorbent dosage } \\
\text { (mg/l) }\end{array}$ & $\underset{(\mathrm{mmol} / \mathrm{g})}{\mathrm{Q}_{\mathrm{e}}}$ & $\mathbf{R} \%$ & \\
\hline \multirow{2}{*}{ MCM } & Cationic & Yellow 87 & 82 & $500-4000$ & $1.17-0.3$ & $25-44$ & (Wu et al. 2012) \\
\hline & Anionic & Remazol Red & 100 & $5-100$ & $0.1-0.3$ & - & (Santos et al. 2013) \\
\hline MPS & Anionic & $\begin{array}{l}\text { Acid Red } 14 \text { (AR14) } \\
\text { Acid Black } 1 \text { (AB1) } \\
\text { Acid Blue } 25 \text { (AB25) }\end{array}$ & 50 & $10-70$ & - & $\begin{array}{l}15-79 \\
10-80 \\
1-1.5\end{array}$ & (Mahmoodi et al. 2011) \\
\hline \multirow{3}{*}{ SBA } & Cationic & Methylene Blue (MB) & 30 & $5-25$ & - & $40-99.1$ & (Dong et al. 2011) \\
\hline & \multirow[t]{2}{*}{ Anionic } & $\begin{array}{l}\text { Acid Blue } 113 \text { (AB-113) } \\
\text { Acid Red } 114 \text { (AR-114) } \\
\text { Acid Green } 28 \text { (AG-28) } \\
\text { Acid Yellow } 127 \text { (AY-127) }\end{array}$ & 100 & $200-400$ & - & $\begin{array}{l}83-93 \\
85-92 \\
95-98 \\
88-94 \\
\end{array}$ & (Anbia and Salehi 2012) \\
\hline & & $\begin{array}{l}\text { Methyl Orange (MO) } \\
\text { Orange G (OG) } \\
\text { Brilliant Red X-3 B (X-3B) }\end{array}$ & 30 & $50-550$ & - & $\begin{array}{l}50-95 \\
40-90 \\
30-70\end{array}$ & (Anbia et al. 2010) \\
\hline
\end{tabular}

aqueous solution. Generally, at low pHs the percentage of a cationic dye removed will decrease while that of an anionic dye will increase (Calvete et al. 2009; Demirbas 2009; Khaled et al. 2009; Ponnusami et al. 2009; Deniz and Karaman 2011; Salleh et al. 2011; Li et al. 2013b; Yan et al. 2013). The point of zero charge $\mathrm{pH}\left(\mathrm{pH}_{\mathrm{pzc}}\right)$ is another important characteristic that determines the $\mathrm{pH}$ at which the adsorbent surface has net electrical neutrality (Gupta et al. 2011). At $\mathrm{pH}<\mathrm{pH}_{\mathrm{pzc}}$, the functional groups are protonated and a positive surface charge dominates. In this case, it is possible to attract negatively charged ions (Malamis and Katsou 2013). The removal of cationic MB dye using 3-aminopropyl triethoxysilane-MPS is increased by increasing $\mathrm{pH}$, and a maximum adsorption capacity of $66 \mathrm{mg} / \mathrm{g}$ is achieved at $\mathrm{pH}=7$ (Karim et al. 2012). The adsorption of YD by Al-MCM- 41 is markedly increased from $23 \%$ at $\mathrm{pH}=2$ to $67 \%$ at $\mathrm{pH} 10$ (Boukoussa et al. 2013). The capacity of dimethyldecylamine-MPS for adsorbing sulphonated azo dye of $0.3 \mathrm{mg} / \mathrm{g}$ is gradually enhanced by decreasing the $\mathrm{pH}$ to less than 4. Increasing $\mathrm{pH}$ resulted in a decrease in adsorption capacity, presumably because of the deprotonation of the surface groups and protonation of the acidic functional groups of Azo dye, leading to an electrostatic repulsion between adsorbent and adsorbate (Yang and Feng 2010a). From the above it is clear that there is an optimum $\mathrm{pH}$ for adsorption and it tends to decrease rapidly at strongly acid or strongly alkaline $\mathrm{pHs}$. The maximum adsorptions of acidic dyes were recorded in solutions with a pH of 2 to 6 and that of cationic dyes of 7 to 11 . In contrast, in a high $\mathrm{pH}$ solution the percentage of cationic dyes removed by adsorption increases and that of anionic dyes decreases. In a high $\mathrm{pH}$ solution, the positive charge at the solution interface decreases and the adsorbent surface appears negatively charged (Bharathi and Ramesh 2013).

\section{Effect of adsorbent dosage}

In order to determine the minimum amount of adsorbent necessary for removing dye from waste water it is important to know what effect adsorbent dose has on dye removal. The effect of adsorbent dosage on the adsorption process is determined by preparing an adsorbentadsorbate solution with different amounts of adsorbents and adding a fixed initial concentration of dye, which are then shaken together until an equilibrium is reached (Salleh et al. 2011; Anbia and Salehi 2012; Karim et al. 2012). It is extensively recorded in the literature that the percentage of the dye adsorbed increases with increase in MSP dosage, but the adsorption capacity $\left(q_{e}, \mathrm{mg} / \mathrm{g}\right)$ decreases with increase in MSP dosage. The effect of MPS dosage on the adsorption of cationic and anionic dyes is summarized in Table 4. For instance, the adsorption AG- 28 by PEHA ${ }^{2}$-SBA- 3 indicates that at a constant concentration of an acid dye and increasing the adsorbent dosage from 0.2 to $0.4 \mathrm{~g} / \mathrm{l}$, increases percentage adsorption from 95.91 to 98.87 , but the adsorption capacity decreases from 479.55 to $247.17 \mathrm{mg} / \mathrm{g}$ (Anbia and Salehi 2012). This is attributed to the significant unsaturation of adsorption sites at high adsorbent dosages. The recorded trend indicates that adsorbent dose affects both the percentage of dye removed and adsorption capacity. Therefore, the optimization of the MPS dosage, in terms of both maximizing the percentage adsorption and adsorption capacity, is an important aspect of removing dye from an aqueous solutions (Bharathi and Ramesh 2013).

\section{Effect of speed of agitation}

Speed of agitation has an important effect on adsorption as it influences the distribution as can be shown by varying the speed of agitation of the adsorbate-adsor-

2 Pentaethylene hexamine. 
Table $\mathbf{5}$ The effect of contact time on dye adsorption process by various MPSs.

\begin{tabular}{|c|c|c|c|c|c|c|c|c|}
\hline Mesoporous silica & & Dye & Experimenta & I condition & & Removal effi & ency & \\
\hline Type & Class & Name & $\begin{array}{l}\text { Dye concentration } \\
\text { (mg/l) }\end{array}$ & $\begin{array}{l}\text { Equilibrium } \\
\text { time (min) }\end{array}$ & pH & $Q_{e}(\mathrm{mmol} / \mathrm{g})$ & $\mathbf{R} \%$ & Ret. \\
\hline \multirow{4}{*}{ SBA } & \multirow{2}{*}{ Cationic } & Methylene Blue & 60 & 60 & $<8$ & 0.78 & - & (Anbia and Hariri 2010) \\
\hline & & Methylene Blue & 30 & 5 & $\geq 8$ & - & 99.1 & (Dong et al. 2011) \\
\hline & \multirow{2}{*}{ Anionic } & Acid Blue 113 & 100 & 60 & 6 & \multirow[t]{2}{*}{0.62} & - & \multirow{2}{*}{ (Anbia and Salehi 2012) } \\
\hline & & Acid Red 114 & 100 & 60 & 6 & & - & \\
\hline MCM & Anionic & Remazol Red & 100 & 360 & 2 & - & 99.1 & (Santos et al. 2013) \\
\hline
\end{tabular}

bent solution while keeping other parameters constant and taking samples at different intervals. Generally the removal of dyes increases with agitation speed (Weng et al. 2009; Bharathi and Ramesh 2013). The mobility of ions in the solution is higher and mass transfer resistance lower if the appropriate speed of agitation is used (Bulut and Karaer 2014). At high agitation rates, the boundary layer becomes thinner, which usually enhances the rate of diffusion of solute through the boundary layer. At high speeds, the value of the external diffusion coefficient is high (Mckay and Poots 1980). In most cases increase in the speed of agitation is associated with an increase in the rate of adsorption, particularly during the early stages of the process. The speed of agitation affects the kinetics but not the equilibrium capacity (Demirbaş and Alkan 2013). Boukoussa et al. (2013) report that the adsorption of YD by calcined and uncalcined Al-MCM- 41 is best studied at $900 \mathrm{rpm}$ as the adsorption efficiency increases by a factor of 2 when the speed of agitation speed is increased from 200 to $900 \mathrm{rpm}$ (Boukoussa et al. 2013). Recently it has been shown that there is a small effect of speed of agitation of more than $150 \mathrm{rpm}$ on the adsorption capacity of acid dyes by PEHA-SBA-3. Increasing the speed from $0 \mathrm{rpm}$ to $150 \mathrm{rpm}$ increases the adsorption capacity of AG-28 from 440 to 480 in $60 \mathrm{~min}$ and the adsorption capacity remained constant at speeds of agitation greater than $150 \mathrm{rpm}$ (Anbia and Salehi 2012). Increasing the speed of agitation decreases the boundary layer resistance to the transfer of adsorbate molecules from the bulk solution to the adsorbent surface. As a result the adsorbate is forced towards the adsorbent surface, which leads to an increase in the diffusion of adsorbate into the surface of the adsorbent (Demirbaş and Alkan 2013; Malamis and Katsou 2013).

\section{Effect of contact time}

The effect of contact time on the adsorption of dye is determined by keeping an adsorbent-adsorbate solution with a fixed adsorbent content and initial concentration of dye for different intervals of time until equilibrium (Bharathi and Ramesh 2013). From an economic point of view contact time provides useful information on the efficiency and feasibility of a full scale operation. For an adsorbent to be efficient in wastewater treatment, it needs to be able to rapidly adsorb the dye and reach equilibrium in a short period of time (Aghayan et al. 2012; Anbia and Salehi 2012; Chen et al. 2012). Data presented in Table 5 show that the adsorption of anionic and cationic dyes by MPSs has a short equilibrium time of 5-60 minutes, which depends on initial concentration of dye. The adsorption of Methylene Blue (MB), a cationic dye, was studied using HPG-COOH${ }^{3}-\mathrm{SBA}-15$. The equilibrium time was $15 \mathrm{~min}$. Moreover $95 \%$ of dye was adsorbed within the first $7 \mathrm{~min}$. This result indicates that HPG-COOH-SBA-15 is a highly efficient adsorbent (Chen et al. 2012). Similarly a short equilibrium time is recorded for the adsorption of MB by Al-SBA-15 (Chang et al. 2013a). Generally, the efficiency with which dyes are removed increases to a certain extent with increase in contact time. Further increase in contact time does not increase the deposition of dyes on the available adsorption sites of the adsorbent material. At this point, the amount of dye desorbing from the adsorbent is in a state of dynamic equilibrium with the amount of dye being adsorbed onto the adsorbent. The time required to attain this state of equilibrium is termed the equilibrium time, and the amount of dye adsorbed at equilibrium time reflects the maximum adsorption capacity of the adsorbent under those operating conditions (Crini and Badot 2008).

\section{Effect of temperature}

Effect of changes in temperature is an indicator of the nature of the adsorption, i.e., whether it is an exothermic or endothermic process (Demirbaş and Alkan 2013). If the adsorption capacity increases with increasing temperature then it is an endothermic process. This may be due to an increase in the mobility of the dye molecules. In addition, the weakening of the physical interactions between dyes and active adsorbent sites could be why there is a decrease in adsorption capacity with increase in temperature. The aqueous solubility of solutes generally increases with increase in temperature, which impedes the adsorption process. a decrease in adsorption capacity with increasing temperature indicates that it is

3 Multicarboxylic hyperbranched polyglycerol. 
Table 6 The effect of temperature on the adsorption process of dyes by various MPSs.

\begin{tabular}{|c|c|c|c|c|c|c|}
\hline \multirow{2}{*}{$\begin{array}{c}\text { Mesoporous silica } \\
\text { Type } \\
\end{array}$} & \multicolumn{2}{|r|}{ Dye } & \multicolumn{2}{|c|}{ Experimental condition } & \multirow{2}{*}{$\begin{array}{c}\text { Adsorption capacity } \\
\mathrm{Q}_{\mathrm{e}}(\mathrm{mmol} / \mathrm{l})\end{array}$} & \multirow{2}{*}{ Ref. } \\
\hline & Class & Name & Temperature range ${ }^{\circ} \mathrm{C}$ & Thermodynamic & & \\
\hline \multirow{3}{*}{ SBA } & \multirow{2}{*}{ Cationic } & Methylene Blue & $30-50$ & Endothermic & $0.62-0.90$ & (Anbia and Hariri 2010) \\
\hline & & Methylene Blue & $20-80$ & - & Unchanged & (Dong et al. 2011) \\
\hline & Anionic & $\begin{array}{l}\text { Acid Blue } 113 \\
\text { Acid Red } 114\end{array}$ & $20-80$ & Exothermic & $\begin{array}{l}0.87-0.79 \\
0.52-0.49\end{array}$ & (Anbia and Salehi 2012) \\
\hline \multirow{2}{*}{ MCM } & Cationic & Yellow 87 & $22-62$ & Exothermic & $0.37-0.47$ & (Wu et al. 2012) \\
\hline & Anionic & Remazol Red & $25-55$ & Endothermic & $0.06-0.07$ & (Santos et al. 2013) \\
\hline MPS & Anionic & Yellow Red & $25-55$ & Endothermic & $0.02-0.06$ & (Cestari et al. 2009) \\
\hline
\end{tabular}

an exothermic process. Increasing temperature may decrease the adsorptive forces between dyes and the active sites on the adsorbent surface as a result of decreasing adsorption capacity (Chowdhury and Saha 2010; Salleh et al. 2011; Bharathi and Ramesh 2013). Also thermodynamic parameters such as changes in Gibbs free energy $(\Delta G)$, enthalpy $(\Delta H)$ and entropy $(\Delta S)$ give information about the adsorption mechanism. The positive values of $\Delta H$ reveal the endothermic nature of adsorption and the possibility of physical adsorption. The negative values of $\Delta G$ reveal that adsorption is highly favourable. The positive values of $\Delta S$ reveal increased disorder and randomness at the solid solution interface of the adsorbent (Demirbas 2009; Ping Ge 2011; Sharma and Das 2012). The effect of temperature on the adsorption capacity of cationic and anionic dyes by MPSs is summarized in Table 6. Adsorption of Yellow 87 dye by uncalcined Al-MCM-41 and MCM-41 is exothermic. In this case, the adsorption decreased from $72 \%$ to $60 \%$ when the temperature increased from 24 to $80{ }^{\circ} \mathrm{C}$. The increase in temperature seems to promote a gradual decrease in the electrostatic interaction between the dye molecules and the surfaces of Al-MCM-41. Moreover, the positive value of $\Delta S$ of adsorption of Yellow 87 dye by MCM41 indicates an increase in the disorder at the solid-solution interface (Wu et al. 2012; Boukoussa et al. 2013). For the adsorption of Methylene blue by Al-MCM-41 the value of $\Delta H$ is negative $(-17.92 \mathrm{~kJ} / \mathrm{mol})$, which indicates an exothermic process (Eftekhari et al. 2010). The same results were obtained by Huang et al. 2011b for the adsorption of Methylene blue by SBA-15 (Huang et al. 2011b). Hence, the adsorption of dyes by MPSs can be either an endothermic or exothermic process depending on the surface chemistry of silica.

\section{Adsorption modeling}

\section{Equilibrium isotherm models}

Adsorption properties and equilibrium data, commonly known as adsorption isotherms, describe how pollutants interact with adsorbent materials and are critical for optimizing the use of adsorbents. In order to op- timize the design of an adsorption system for removing dye from solutions it is important to establish the most appropriate correlation for the equilibrium curve. An accurate mathematical description of equilibrium adsorption capacity is indispensable for reliable prediction of the adsorption parameters and quantitative comparison of adsorption behaviour in different adsorbent systems (or for various experimental conditions) in any given system (Gupta and Suhas 2009).

Adsorption equilibrium is established when the amount of dye being adsorbed onto the adsorbent is equal to the amount being desorbed. It is possible to depict the equilibrium adsorption isotherms by plotting the concentration of the dye in the solid phase against that in the liquid phase. The distribution of dye molecules in the liquid phase and the sorbent is a measure of the position of equilibrium in the adsorption process and can generally be expressed by one or more of a series of isotherm models. The shape of an isotherm may be used to predict if a sorption system is "favourable" or "unfavourable". The shape of the isotherm can also provide qualitative information on the nature of the solute-surface interaction (Dąbrowski 2001; Demirbas 2004; Sud et al. 2008; Salleh et al. 2011). There are many isotherms that describe sorption such as Langmuir, Freundlich, BET, Toth, Temkin, Redlich-Peterson, Sips, Frumkin, Harkins-Jura, Halsey, Henderson and Dubinin-Radushkevich. For designing

Table 7 The mathematical equations of isotherm models.

\begin{tabular}{|l|l|}
\hline Isotherm & Equation \\
\hline Langmuir & $C_{e} / q_{e}=1 / k_{L}+\left(a_{L} / k_{L}\right) C_{e}$ \\
\hline Freundlich & $\ln q_{e}=\ln q_{F}+1 / n_{F} \times \ln C_{e}$ \\
\hline Redrich-Peterson & $q_{e}=K_{R P} C_{e} / 1+a C_{e}^{g}$ \\
\hline Temkin & $q_{e}=B \ln K_{t}+B \ln C_{e}$ \\
\hline
\end{tabular}

$C_{e}$ : dye concentration at equilibrium ( $\left.\mathrm{mg} / \mathrm{l}\right) ; q_{e}$ : amount of dye adsorbed at equilibrium $(\mathrm{mg} / \mathrm{g}) ; K_{L}$ : the Langmuir isotherm constant $(\mathrm{l} / \mathrm{g}) ; a_{L}$ : the Langmuir isotherm constant $(\mathrm{l} / \mathrm{mg}) ; K_{F}(\mathrm{l} / \mathrm{g})$ and $n_{F}$ : the Freundlich isotherm constant; $K_{R P}$ and a: the Redlich-Peterson constants; $g$ is the exponent which lies between 0 and 1 ( $g=1$ reduces it to Langmuir form); $K_{t}$ : the Temkin equilibrium binding constant $(\mathrm{I} / \mathrm{mg})$ corresponding to the maximum binding energy; $B$ : the constant related to the heat of adsorption. 
the optimum adsorption system it is important to first establish the most appropriate equilibrium curve (Crini and Badot 2008; Yadla et al. 2012).

The most frequently used equations for describing isotherms of the adsorption of dye by MPSs in solid/ liquid systems are the Langmuir (Joo et al. 2009; Chen et al. 2012; Chang et al. 2013a; Liu et al. 2013), Freundlich (Monash and Pugazhenthi 2009; Anbia et al. 2010; Anbia and Salehi 2012), Redlich-Peterson (Monash and Pugazhenthi 2009; Yang and Feng 2010a; Wu et al. 2012) and Temkin (Anbia and Hariri 2010; Mahmoodi et al. 2011). The mathematical equations of these models are presented in Table 7.

There is little literature on the isotherm modeling of dye adsorption by MSPs. (Table 8). The Langmuir model is the most appropriate one for describing adsorption in the case of MB (Huang et al. 2011a) and BV-10 (Juang et al. 2006) by MPSs, and Remazol Red (Asouhidou et al. 2009) and MB (Chang et al. 2013b) by functionalized MPSs. The adsorption of Rifazol Yellow GR, Rifazol Red BB 150 and Rifafix Yellow 3 RN150H by PDDA-SBA-15 are well described by the Langmuir isotherm model $\left(R^{2}>\right.$ 0.999 ), in which the steep increase in adsorption capacity $(120,240,340 \mathrm{mg} / \mathrm{g}$ respectively) indicates a great affinity of the adsorbent for dyes, followed by a plateau, which indicates the maximum capacity when the monolayer is saturated (Joo et al. 2009). Similar conclusions are reported for the adsorption of the dyes AR14, AB1 and AB25 by amine-functionalized-MPSs. In this case, the adsorbed layer is one molecule thick and the sites homogeneous, which confirms the suitability of the Langmuir model (Mahmoodi et al. 2011). Multilayer adsorption of the dyes RB, CV and MG by MCM- 41 is best described by the Freundlich model. Moreover multilayer adsorption does occur (Lee et al. 2007). Studies of adsorption of MG by Tren-SBA-15 indicate that both Freundilch and Sips models describe the experimental data well. The value of the Sips isotherm constant, $n_{S}$, is greater than unity, indicating system heterogeneity, which could be attributed to the arm-like structure of the Tren groups that probably capture the MG molecules of various shapes (Badiei et al. 2014). The Langmuir and Redlich-Peterson isotherm models can accurately describe the overall adsorption equilibria of $\mathrm{MB}$, phenosafranine and night blue by carboxylate-functionalized-MPS (C-MPS), which indicates a single surface reaction with constant activation energy predominates and that monolayer adsorption occurs in all of these sorption processes (Yan et al. 2006b).

\section{Kinetic}

Dynamics of the adsorption process can be understood by evaluating kinetic data (Deniz and Karaman 2011; Rehman et al. 2012). Kinetic aspects of adsorption provide useful data for determining the feasibility of scale-up operations and valuable information on the mechanism of the adsorption process (Calvete et al. 2009; Feng et al. 2012). When choosing the material to be used as an adsorbent not only should it have a large adsorption capacity, but also a high mass transfer rate and fast adsorption kinetic (Ho and Mckay 1999; Qiu et al. 2009; Aghayan et al. 2012; Gandhimathi et al. 2012). Kinetic modelling allows both the adsorption rates and characteristics of possible reaction mechanisms, along with suitable rate expressions, to be estimated (Ho and Mckay 1999). It is usually necessary to carry out experimental studies using several variables to test data in order to confirm whether the mechanism is film diffusion, diffusion sorption or a combination of these processes (Ho et al. 2000). Three kinetic models (Table 9) are widely used to describe the adsorption of dye by MPSs: (i) pseudo-first-order kinetic model (Lagergren model) (Parab et al. 2009); (ii) pseudo-second-order kinetic model (Ho and McKay model) (Mahmoodi et al. 2011); (iii) intraparticle diffusion model (Webber and Morris model) (Qin et al. 2009).

Table $\mathbf{8}$ Isotherm studies of dye adsorption by various MPSs.

\begin{tabular}{|c|c|c|c|c|c|c|c|c|}
\hline \multirow{2}{*}{$\frac{\text { Mesoporous silica }}{\text { Type }}$} & \multicolumn{2}{|r|}{ Dye } & \multicolumn{5}{|c|}{ Experimental result } & \multirow[b]{2}{*}{ Ref. } \\
\hline & Class & Name & Isotherm & $\underset{(\mathrm{mmol} / \mathrm{g})}{\mathbf{Q}_{\max }}$ & $\begin{array}{c}\mathrm{K}_{\mathrm{L}} \\
(\mathrm{I} / \mathrm{mg})\end{array}$ & $\begin{array}{c}\mathrm{K}_{\mathbf{f}} \\
(\mathrm{mmol} / \mathrm{g})\end{array}$ & $\mathbf{R}^{2}$ & \\
\hline \multirow{6}{*}{ MCM } & \multirow{2}{*}{ Cationic } & Crystal Violet & Freundlich & 0.2 & - & 0.363 & 0.976 & (Monash and Pugazhenthi 2009) \\
\hline & & Basic Violet 10 & Langmuir & 1.14 & $1.91 \times 10^{-2}$ & - & 0.999 & (Juang et al. 2006) \\
\hline & \multirow{4}{*}{ Anionic } & \multirow{4}{*}{$\begin{array}{l}\text { Methyl Orange } \\
\text { Orange Iv } \\
\text { Acid Fuchsine } \\
\text { Red X-3B }\end{array}$} & Langmuir & \multirow{4}{*}{$\begin{array}{l}1.12 \\
1.09 \\
0.43 \\
0.34\end{array}$} & - & - & 0.999 & (Qin et al. 2009) \\
\hline & & & Langmuir & & - & - & 0.999 & (Qin et al. 2009) \\
\hline & & & Langmuir & & - & - & 0.999 & (Qin et al. 2009) \\
\hline & & & Langmuir & & - & - & 0.999 & (Qin et al. 2009) \\
\hline \multirow{3}{*}{ SBA } & \multirow{3}{*}{ Cationic } & Methylene Blue & Freundlich & 0.07 & - & 0.185 & 0.991 & (Huang et al. 2011b) \\
\hline & & Methylene Blue & Langmuir & 0.50 & - & - & 0.999 & (Chen et al. 2012) \\
\hline & & Methylene Blue & Langmuir & 0.16 & 33.03 & - & 0.976 & (Huang et al. 2011a) \\
\hline \multirow{3}{*}{ MPS } & \multirow{3}{*}{ Anionic } & Red Sbrilliant & Langmuir & 0.35 & \multirow{3}{*}{$\begin{array}{r}9.23 \\
55.92 \\
12.92\end{array}$} & - & \multirow{3}{*}{$\begin{array}{l}0.999 \\
0.998 \\
0.974\end{array}$} & (Yan et al. 2006b) \\
\hline & & Red X-3B & Langmuir & 1.10 & & - & & (Yan et al. 2006b) \\
\hline & & Yellow X-RG & Langmuir & 2.25 & & - & & (Yan et al. 2006b) \\
\hline
\end{tabular}


Table 9 The three most popular kinetic models.

\begin{tabular}{|l|l|}
\hline Kinetic model & Formula \\
\hline Pseudo-first-order reaction & $\log \left(q_{e}-q_{t}\right)=\log \left(q_{e}\right)-K_{l} / 2.303 t$ \\
\hline Pseudo-second-order reaction & $1 / q_{t}=1 / k_{2} q_{e}^{2}+1 / q_{e} t$ \\
\hline Intraparticle diffusion & $q_{t}=k_{i} t^{1 / 2}+c$ \\
\hline
\end{tabular}

$q_{e}(\mathrm{mg} / \mathrm{g})$ : amount of adsorbed dye on the adsorbent at equilibrium; $q_{t}(\mathrm{mg} / \mathrm{g})$ : the amount of adsorbed dye on the adsorbent at time $\mathrm{t}_{\text {; }}$ $k_{1}\left(\mathrm{~min}^{-1}\right)$ : the rate constant for first-order adsorption; $k_{2}(\mathrm{~g} / \mathrm{mg} \mathrm{min})$ : the pseudo-second order rate constant (Deniz and Karaman 2011)

Sometimes the pseudo-first-order model is not a good fit over the whole range of contact times and fails to predict the amount of dye adsorbed. In this case, the pseudo-second-order equation, which is based on the sorption capacity of the solid phase and assumes that chemisorption may be the rate-controlling step in the adsorption processes, can be used (Salleh et al. 2011). Pseudo-second order kinetics are usually associated with situations when the rate of direct adsorption/desorption process controls the overall sorption kinetics (Plazinski et al. 2009). The advantage of using the pseudo-second-order model is that there is no need to know the equilibrium capacity, as it can be calculated from the model. In addition, the initial adsorption rate can also be obtained from the model (Ho 2006; Plazinski et al. 2009). Usually, the best-fitting model is selected based on the value of the regression correlation coefficient $\left(R^{2}\right)$. Generally, kinetic adsorption is better represented by the pseudo-second-order model for anionic and cationic dye adsorption. Studies on adsorption kinetics of dyes by MPSs are summarized in Table 10.

Three consecutive mass transfer steps are associated with the adsorption of solute from solution by MPSs, any of which could be the rate-controlling factor. First, the adsorbate migrates through the external boundary layer film of the liquid surrounding the outside of the particle, followed by solute movement from the surface of the particles into internal sites by pore and/or surface diffusion, and finally the adsorbate is adsorbed onto active sites in the interior of the adsorbent particles. The final step is assumed to be faster than the first two steps and is, thus, not considered in kinetic analyses. The kinetics of the adsorption of Yellow 87 by MCM41 has been studied using the pseudo-first-order and pseudo-second-order kinetic models. The values of the pseudo-second-order rate constant increases with increasing concentration of the dye from 0.025 to $0.250 \mathrm{mg} / \mathrm{l}$. The $R^{2}$ values were closer to unity for the pseudo-second-order model. Moreover, during the initial stage of the adsorption process, rapid removal of basic yellow 87 was recorded in the first $10 \mathrm{~min}$. These results indicate that there is a higher-affinity between the dye molecules and the surface of MCM41 than for AC due to rapid adsorption (Wu et al. 2012). The high $R^{2}$ values (>0.99) indicate that the adsorption process of MB and JGB by SBA-15 is well described by the pseudo-second-order rate equation. In addition, the adsorption rate constant $\mathrm{k}_{2}$ of $\mathrm{MB}$, which has a smaller molecular size, is larger than that of JGB at each temperature (e.g. 16.71 and $7.34 \mathrm{~g} / \mathrm{mmol} \mathrm{min}$ at $65^{\circ} \mathrm{C}$, respectively) (Huang et al. 2011b). The adsorption of MB and $\mathrm{RhB}$ from aqueous solution by titania-MPS indicates that the adsorption kinetics is best described by the first-order model (Messina and Schulz 2006). The adsorption of anionic dyes by $\mathrm{NH}_{3}{ }^{+}-\mathrm{MCM}-41$ revealed that an increase in the concentration of dye results in an increase in the driving force, which consequently increases the diffusion rate of the molecular dye from the bulk phase to the exterior surface of the adsorbent. Qin et al. (2009) report that the order of $\Delta \mathrm{q}_{\mathrm{e}}$ (difference between experimental and predicted $\mathrm{q}_{\mathrm{e}}$ ) is pseudo-first > pseudo-second $>$ in-

Table 10 Kinetic modelling of dye adsorption by MPSs.

\begin{tabular}{|c|c|c|c|c|c|c|}
\hline \multirow{2}{*}{$\begin{array}{c}\begin{array}{c}\text { Mesoporous } \\
\text { silica }\end{array} \\
\text { Type } \\
\end{array}$} & \multicolumn{2}{|r|}{ Dye } & \multicolumn{2}{|c|}{ Experimental result } & \multirow{2}{*}{$\begin{array}{c}\text { Adsorption capacity } \\
\mathbf{Q}_{\mathrm{e}}(\mathrm{mmol} / \mathrm{g})\end{array}$} & \multirow{2}{*}{ Ref. } \\
\hline & Class & Name & Kinetic & $\mathbf{R}^{2}$ & & \\
\hline \multirow{5}{*}{ MCM } & \multirow{5}{*}{ Cationic } & Methylene Blue & Pseudo-second-order & 0.967 & 0.03 & (Wang and Li 2006) \\
\hline & & Methylene Blue & Pseudo-second-order & 0.936 & 0.03 & (Wang and Li 2006) \\
\hline & & Crystal Violet & Pseudo-second-order & 0.998 & 0.14 & (Monash and Pugazhenthi 2009) \\
\hline & & Methylene Blue & Pseudo-second-order & 0.999 & 0.08 & (Eftekhari et al. 2010) \\
\hline & & Rhodamine B & Pseudo-second-order & 0.999 & 0.2 & (Eftekhari et al. 2010) \\
\hline \multirow{4}{*}{ MPS } & \multirow{4}{*}{ Anionic } & Acid Red 14 & Pseudo-second-order & $<0.998$ & - & (Mahmoodi et al. 2011) \\
\hline & & Acid Black 1 & Pseudo-second-order & $<0.998$ & - & (Mahmoodi et al. 2011) \\
\hline & & Acid Blue 25 & Pseudo-second-order & $<0.998$ & - & (Mahmoodi et al. 2011) \\
\hline & & Remazol Red & Second-order & 0.991 & 0.12 & $\begin{array}{l}\text { (Asouhidou et al. 2009, } \\
\text { Carmen and Daniela 2012) }\end{array}$ \\
\hline \multirow{3}{*}{ SBA } & \multirow{3}{*}{ Cationic } & Methylene Blue & Pseudo-second-order & 0.999 & 1.49 & (Huang et al. 2011b) \\
\hline & & Janus Green B & Pseudo-second-order & 0.999 & 1.29 & (Huang et al. 2011b) \\
\hline & & Methylene Blue & Pseudo-second-order & 0.999 & 0.5 & (Chen et al. 2012) \\
\hline
\end{tabular}


Table 11 Desorption of dye saturated MPSs.

\begin{tabular}{|c|l|l|l|l|c|l|}
\hline Mesoporous silica & \multicolumn{2}{|c|}{ Dye } & \multicolumn{3}{c|}{ Experimental condition } & \multirow{2}{*}{ Ref. } \\
\hline \multirow{2}{*}{ Type } & \multicolumn{1}{|c|}{ Class } & \multicolumn{1}{|c|}{ Name } & \multicolumn{1}{|c|}{ Solvent } & \multicolumn{1}{c|}{ Desorption rate } & No. of cycles & \\
\hline \multirow{2}{*}{ MPS } & \multirow{2}{*}{ Anionic } & Acid Fuchsine & $\mathrm{NaOH}$ & More than 82\% & 4 & (Li et al. 2013) \\
\cline { 2 - 8 } & & Congo Red & $\mathrm{H}_{2} \mathrm{O}-$-ethanol & More than 80\% & 4 & (Li et al. 2013) \\
\cline { 2 - 7 } & Cationic & Methylene Blue & $\mathrm{HCl}$ & $99 \%$ & 5 & (Chang et al. 2013b) \\
\hline MCM & Anionic & Remazol Red & $\mathrm{NaOH}$ & $98.2 \%$ & - & (Juang et al. 2007) \\
\hline
\end{tabular}

traparticle diffusion model for four types of anionic dyes, which indicates that the intraparticle diffusion model is the best description of the adsorption kinetics of anionic dyes by $\mathrm{NH}_{3}{ }^{+}$-MCM-41 (Qin et al. 2009). Overall, the studies indicate that the pseudo-second-order rate equation provides a reasonably good fit to the data on dye adsorption by MPSs.

\section{Multi-component adsorption}

The prediction of the multi-component equilibrium data has always been complicated due to the interactive and competitive effects involved. Nevertheless, there have been attempts to predict and correlate multi-component data from single component data (Turabik 2008). The adsorption of Acid blue 25 and Methylene blue dye by $\mathrm{NH}_{2}$ MPS in the binary system has been reported by Ho et al. (2003). In competitive adsorption experiments Acid blue $25(250 \mathrm{mg} / \mathrm{g})$ is adsorbed preferentially over $\mathrm{NH}_{2}$-MPS . These authors suggest that the adsorbed dye molecules change the chemical characteristics of the MPS, which then interacts with the cationic MB dye in the solution leading to multilayer adsorption and the enhancement in the adsorption of methylene blue by $\mathrm{NH}_{2}$-MPS. The competitive adsorption of $\mathrm{MB}$ and $\mathrm{RB}$ by Al-MCM-41 in binary system form $8 \times 10^{-6} \mathrm{M}$ dye solution was studied by Eftekhari et al. (2010). In comparison with RB, the smaller size of $\mathrm{MB}$ provides the necessary driving force to overcome the resistances to mass transfer resulting in a higher sorption capacity (Eftekhari et al. 2010). In general, in a binary system, competition (total or partial) between adsorbate species to occupy sorbent sites on the solid surface occur and may act as a sorption-controlling factor. Such phenomena result in the solid surface being covered by both adsorbates with certain fractional loadings. Moreover, the adsorption potential of the surface is also affected by lateral interaction or competition between adsorbate species (Kurniawan et al. 2012).

\section{Desorption studies}

That an adsorbent can be repeatedly used to adsorb and desorb without loss of adsorption capacity is an important feature of an adsorbent. Desorption is usually achieved by mixing a suitable solvent with the dye-sat- urated substrate, shaking the mixture until the dye is extracted from the solvent and then using filtration to separate the adsorbent (Bharathi and Ramesh 2013). Studies of desorption help us to understand the adsorption mechanism. If the adsorbed dyes can be desorbed using water at a neutral $\mathrm{pH}$, then the bonds attaching the dye to the adsorbent are weak. If the dye is desorbed in alkaline water, then adsorption is by ion-exchange. If the dye is desorbed in an organic acid, then adsorption is by chemisorption (Salleh et al. 2011; Bharathi and Ramesh 2013). Table 11 lists studies on desorption of dyes from various MPSs.

$\mathrm{MB}$ and $\mathrm{AO}$ can be desorbed from carboxylic-magnetic-MPS by washing it with ethanol at $\mathrm{pH} 3$ with an equilibrium time of $6 \mathrm{~min}$. The percentage desorption of $\mathrm{MB}$ and $\mathrm{AO}$ was above $91.0 \%$ for different concentrations of dye. The regenerated adsorbents were treated with deionized water to neutralize and then vacuum dried at $333 \mathrm{~K}$ overnight. After seven successive adsorption-desorption cycles there were no changes in the sorption behaviour. Desorption efficiency was above $88 \%$ in the final cycle (Fu et al. 2011). Desorption of Remazol Red from HMS was carried out by surfactant enhanced regeneration. The results indicate that HMS can be used repeatedly desorbed three times without significant loss of its adsorption capabilities (Asouhidou et al. 2009). To evaluate the possibility of regenerating $\mathrm{MB}$ saturated SBA-15 adsorbent, desorption was carried out. The result indicates that the fading rate for the MB solution was almost unaffected even after the tenth run with regenerated SBA-15 (Dong et al. 2011). According to the literature, MPSs can be easily recovered and recycled but the data is insufficient for drawing a firm conclusion. Therefore, more research works is needed and it should focus on the regeneration of MPSs.

\section{Conclusion and suggestions}

In this paper the use of MPSs as adsorbents for removing dyes from aqueous solutions is reviewed. MPSs have a great potential for removing dyes and could be used commercially. This paper attempts to highlight the effect of the class of dye on the adsorption process and reviews some of the studies on adsorption of dyes by various MPSs. Based on the literature, functionalized MPSs are better at adsorbing dyes than MPSs; especially 
those functionalized with amine and branched polymer groups. The most important factor affecting adsorption is $\mathrm{pH}$, with a high $\mathrm{pH}$ best for cationic dye adsorption, whereas an increase in $\mathrm{pH}$ results in a significant decrease in the adsorption of anionic dyes. The adsorption efficiency also increases with increase in adsorbent dosage and contact time. The Langmuir model is usually used to evaluate the adsorption capacity of MPSs. Although, a lot of work has been done on the adsorption efficiency of MPSs further studies are needed on cost effectiveness of using them to remove dye from industrial effluents. Since there are a variety of MPSs based adsorbents, arguments on which type of adsorbent is the best will continue. There is no definite answer to this debate since each of the adsorbents has its own advantages and disadvantages. This review indicates there is a great opportunity for improvement resulting in MPSs being used commercially instead of only in the laboratory.

\section{Acknowledgements}

Authors gratefully acknowledge the "Iran Nano Technology Initiative Council” for supporting this work.

\section{REFERENCES}

Addy M, Losey B, Mohseni R, Zlotnikov E, Vasiliev A (2012) Adsorption of heavy metal ions on mesoporous silica-modified montmorillonite containing a grafted chelate ligand. Appl Clay Sci 59: 115-120.

Aghayan H, Mahjoub AR, Khanchi AR (2012) Immobilization of Tin (IV) molybdophosphate onto mesoporous silica SBA-15 and its application on strontium removal from aqueous solution. Appl Surf Sci 261: 14-20.

Aguado J, Arsuaga JM, Arencibia A, Lindo M, Gascón V (2009) Aqueous heavy metals removal by adsorption on amine-functionalized mesoporous silica. J Hazard Mater 163: 213-221.

Alothman ZA (2012) A review: fundamental aspects of silicate mesoporous materials. Mater Chem Phys 5: 2874-2902.

Anbia M, Hariri SA (2010) Removal of methylene blue from aqueous solution using nanoporous SBA-3. Desalination 261: 61-66.

Anbia M, Hariri SA, Ashrafizadeh SN (2010) Adsorptive removal of anionic dyes by modified nanoporous silica SBA-3. Appl Surf Sci 256: 3228-3233.

Anbia M, Salehi S (2012) Removal of acid dyes from aqueous media by adsorption onto amino-functionalized nanoporous silica SBA-3. Dyes Pigments 94: 1-9.

Asouhidou DD, Triantafyllidis KS, Lazaridis NK, Matis KA (2009) Adsorption of Remazol Red 3BS from aqueous solutions using APTES and Cyclodextrin-modified HMS-type mesoporous silicas. Colloids Surf A 346: 83-90.

Badiei A, Mirahsani A, Shahbazi A, Younesi H, Alizadeh M (2014) Adsorptive removal of toxic dye.from aqueous solution and real industrial effluent by tris (2-aminoethyl) amine functionalized nanoporous silica. Environ Prog Sustain Energy 33: 1242-1250.

Balati A, Shahbazi A, Amini MM, Hashemi SH, Jadidi K (2014) Comparison of the efficiency of mesoporous silicas as absor- bents for removing naphthalene from contaminated water. Eur J Environ Sci 4: 69-76.

Banat IM, Nigam P, Singh D, Marchant R (1996) Microbial decolorization of textile-dye containing effluents: a review. Bioresour Technol 58: 217-227.

Bharathi K, Ramesh S (2013) Removal of dyes using agricultural waste as low-cost adsorbents: a review. Appl Water Sci 3: 773-790.

Boukoussa B, Hamacha R, Morsli A, Bengueddach A (2013) Adsorption of yellow dye on calcined or uncalcined Al-MCM-41 mesoporous materials. Arabian J Chem (in press), doi: 10.1016/j.arabjc.2013.07.049.

Bulut Y, Karaer H (2014) Adsorption of methylene blue from aqueous solution by crosslinked chitosan/bentonite composite. J Dispersion Sci Technol 1: 61-67.

Calvete T, Lima EC, Cardoso NF, Dias SLP, Pavan FA (2009) Application of carbon adsorbents prepared from the Brazilian pinefruit-shell for the removal of Procion Red MX 3B from aqueous solution - Kinetic, equilibrium, and thermodynamic studies. Chem Eng J 155: 627-636.

Carmen Z, Daniela S (2012) Textile organic dyes - Characteristics, polluting effects and separation/elimination procedures from industrial effluents - A critical overview. doi: 10.5772/32373. In: Puzyn T, Mostrag-Szlichtyng A (eds) Organic pollutants ten years after the Stockholm Convention - Environmental and analytical update.

Cestari AR, Vieira EF, Vieira GS, Almeida LE (2007) Aggregation and adsorption of reactive dyes in the presence of an anionic surfactant on mesoporous aminopropyl silica. J Colloid Interface Sci 309: 402-411.

Cestari AR, Vieira EFS, Vieira GS, Da Costa LP, Tavares AMG, Loh W, Airoldi C (2009) The removal of reactive dyes from aqueous solutions using chemically modified mesoporous silica in the presence of anionic surfactant - The temperature dependence and a thermodynamic multivariate analysis. J Hazard Mater 161: 307-316.

Chang F, Wang G, Xie Y, Zhang M, Zhang J, Yang HJ, Hu X (2013a) Synthesis of $\mathrm{TiO}_{2}$ nanoparticles on mesoporous aluminosilicate Al-SBA-15 in supercritical $\mathrm{CO}_{2}$ for photocatalytic decolorization of methylene blue. Ceram Int 39: 3823-3829.

Chang WC, Deka JR, Wu HY, Shieh FK, Huang SY, Kao HM (2013b). Synthesis and characterization of large pore cubic mesoporous silicas functionalized with high contents of carboxylic acid groups and their use as adsorbents. Appl Catal B 142: 817-827.

Chen Z, Zhou L, Zhang F, Yu C, Wei Z (2012) Multicarboxylic hyperbranched polyglycerol modified SBA-15 for the adsorption of cationic dyes and copper ions from aqueous media. Appl Surf Sci 258: 5291-5298.

Chew TL, Ahmad AL, Bhatia S (2010) Ordered mesoporous silica (OMS) as an adsorbent and membrane for separation of carbon dioxide $\left(\mathrm{CO}_{2}\right)$. Adv Colloid Interface Sci 153: 43-57.

Choudhary VR, Mantri K (2000) Temperature programmed desorption of toluene, xylene, mesitylene and naphthalene on mesoporous high silica MCM-41 for characterizing its surface properties and measuring heats of adsorption. Micropor Mesopor Mater 40: 127-133.

Chowdhury S, Saha P (2010) Sea shell powder as a new adsorbent to remove Basic Green 4 (Malachite Green) from aqueous solutions: Equilibrium, kinetic and thermodynamic studies. Chem Eng J 164: 168-177.

Crini G (2006) Non-conventional low-cost adsorbents for dye removal: a review. Bioresour Technol 97: 1061-1085. 
Crini G, Badot PM (2008) Application of chitosan, a natural aminopolysaccharide, for dye removal from aqueous solutions by adsorption processes using batch studies: a review of recent literature. Prog Polym Sci 33: 399-447.

Dąbrowski A (2001) Adsorption-from theory to practice. Adv Colloid Interface Sci 93: 135-224.

Debnath S, Kitinya J, Onyango MS (2013) Removal of Congo Red from aqueous solution by two variants of calcium and iron based mixed oxide nano-particle agglomerates. J Ind Eng Chem 4: 2119-2129.

Demirbas A (2004) Adsorption of lead and cadmium ions in aqueous solutions onto modified lignin from alkali glycerol delignication. J Hazard Mater 109: 221-226.

Demirbas A (2009) Agricultural based activated carbons for the removal of dyes from aqueous solutions: a review. J Hazard Mater 167: 1-9.

Demirbaş Ö, Alkan M (2013) Adsorption kinetics of a cationic dye from wastewater. Desalination Water Treat (in press), doi: 10.1080/19443994.2013.874705.

Deniz F, Karaman S (2011) Removal of an azo-metal complex textile dyes from colored aqueous solutions using an agro-residue. Microchem J 99: 296-302.

Dong Y, Lu B, Zang S, Zhao J, Wang X, Cai Q (2011) Removal of methylene blue from colored effluents by adsorption onto SBA-15. J Chem Technol Biotechnol 86: 616-619.

Dos Santos AB, Cervantes FJ, Van Lier JB (2007) Review paper on current technologies for decolourisation of textile wastewaters: Perspectives for anaerobic biotechnology. Bioresour Technol 98: 2369-2385.

Dou B, Hu Q, Li J, Qiao S, Hao Z (2011) Adsorption performance of VOCs in ordered mesoporous silicas with different pore structures and surface chemistry. J Hazard Mater 186: 1615-1624.

Eftekhari S, Habibi A, Sohrabnezhad S (2010) Application of AlMCM-41 for competitive adsorption of methylene blue and rhodamine B: Thermodynamic and kinetic studies. J Hazard Mater 178: 349-355.

Fatimah I, Wang S, Wulandari D (2011) ZnO/montmorillonite for photocatalytic and photochemical degradation of methylene blue. Appl Clay Sci 53: 553-560.

Feng Y, Zhou H, Liu G, Qiao J, Wang J, Lu H, Yang L, Wu Y (2012) Methylene Blue adsorption onto swede rape straw (Brassica napus L.) modified by tartaric acid: Equilibrium, kinetic and adsorption mechanisms. Bioresour Technol 125: 138-144.

Fu X, Chen X, Wang J, Liu J (2011) Fabrication of carboxylic functionalized superparamagnetic mesoporous silica microspheres and their application for removal basic dye pollutants from water. Micropor Mesopor Mater 139: 8-15.

Gandhimathi R, Ramesh ST, Sindhu V, Nidheesh PV (2012) Single and tertiary system dye removal from aqueous solution using bottom ash: Kinetic and isotherm studies. Iranica J Energy Environ 1: 52-62.

Gregory P (2009) Dyes and dye intermediates. Kirk-Othmer Encyclopedia of Chemical Technology. Copyright by John Wiley and Sons, Inc.

Gupta N, Kushwaha AK, Chattopadhyaya MC (2011) Application of potato (Solanum tuberosum) plant wastes for the removal of methylene blue and malachite green dye from aqueous solution. Arabian J Chem (in press), doi: 10.1016/j.arabjc.2011.07.021.

Gupta VK, Suhas (2009) Application of low-cost adsorbents for dye removal - A review. J Environ Manage 8: 2313-2342.

Herbst W, Hunger K (2007) Industrial dyes: Chemistry, properties, applications. John Wiley and Sons.

Ho KY, Mckay G, Yeung KL (2003) Selective adsorbents from ordered mesoporous silica. Langmuir 19: 3019-3024.
Ho YS (2006) Review of second-order models for adsorption systems. J Hazard Mater 136: 681-689.

Ho Y, Ng J, Mckay G (2000) Kinetics of pollutant sorption by biosorbents: review. Sep Purif Reviews 29: 189-232.

Ho YS, Mckay G (1999) Pseudo-second order model for sorption processes. Process Biochem 34: 451-465.

Hoffmann F, Cornelius M, Morell J, Fröba M (2006) Silica-Based mesoporous organic-inorganic hybrid materials. Angew Chem Int Ed 45: 3216-3251.

Huang $\mathrm{CH}$, Chang KP, Ou HD, Chiang YC, Chang EE, Wang CF (2011a) Characterization and application of Ti-containing mesoporous silica for dye removal with synergistic effect of coupled adsorption and photocatalytic oxidation. J Hazard Mater. 186: 1174-1182.

Huang CH, Chang KP, Ou HD, Chiang YC, Wang CF (2011b) Adsorption of cationic dyes onto mesoporous silica. Micropor Mesopor Mater 14: 102-109.

Huang Y (2009) Functionalization of mesoporous silica nanoparticles and their applications in organo-, metallic and organometallic catalysis. Graduate Theses Dissertations.

Hunger K (2002) Industrial dyes: important chemical chromophores of dye classes. John Wiley and Sons.

Joo JB, Park J, Yi J (2009) Preparation of polyelectrolyte-functionalized mesoporous silicas for the selective adsorption of anionic dye in an aqueous solution. J Hazard Mater 168: 102-107.

Juang LC, Wang CC, Lee CK (2006) Adsorption of basic dyes onto MCM-41. Chemosphere 64: 1920-1928.

Juang LC, Wang CC, Lee CK, Hsu TC (2007) Dyes adsorption onto organoclay and MCM-41. J Environ Eng Manage 1:29-38.

Karim AH, Jalil AA, Triwahyono S, Sidik SM, Kamarudin NHN, Jusoh R et al. (2012) Amino modified mesostructured silica nanoparticles for efficient adsorption of Methylene Blue. J Colloid Interface Sci 386: 307-314.

Khaled A, Nemr AE, Sikaily A, Abdelwahab O (2009) Removal of Direct N Blue-106 from artificial textile dye effluent using activated carbon from orange peel: Adsorption isotherm and kinetic studies. J Hazard Mater 165: 100-110.

Kim BC, Lee J, Um W, Kim J, Joo J, Lee JH et al. (2011) Magnetic mesoporous materials for removal of environmental wastes. J Hazard Mater 192: 1140-1147.

Kulkarni SV, Ruppersberger JS (1985) Textile dyes and dyeing equipment: Classification, properties, and environmental aspects. Air and Energy Engineering Research Laboratory, Office of Research and Development, US Environmental Protection Agency.

Kurniawan A, Sutiono H, Indraswati N, Ismadji S (2012) Removal of basic dyes in binary system by adsorption using rarasaponin-bentonite: Revisited of extended Langmuir model. Chem Eng J 189: 264-274.

Laing D, Dudley R, Hartshorne A, Home J, Rickard R, Bennett D (1991) The extraction and classification of dyes from cotton and viscose fibres. Forensic Sci Int 50: 23-35.

Lallas PL (2001) Stockholm Convention on Persistent Organic Pollutants. Hein Online.

Lee CK, Liu SS, Juang LC, Wang CC, Lin KS, Lyu MD (2007) Application of MCM-41 for dyes removal from wastewater. J Hazard Mater 147: 997-1005.

Li G, Zhao Z, Liu J, Jiang G (2011) Effective heavy metal removal from aqueous systems by thiol functionalized magnetic mesoporous silica. J Hazard Mater 192: 277-283.

Li Y, Du Q, Liu T, Sun J, Wang Y, Wu S, Wang Z, Xia Z, Xia L (2013) Methylene Blue adsorption on graphene oxide/calcium alginate composites. Carbohydr Polym 95: 501-507.

Lichtfouse E, Robert D, Schwarzbauer J (2005) Environmental chemistry. Springer, Berlin. 
Limaye VV, Ruparelia J (2011) Reduction of ice usage in dyes industry. Institute Technol 4: 382-481.

Liu J, Feng X, Fryxell GE, Wang LQ, Kim AY, Gong M (1998) Hybrid mesoporous materials with functionalized monolayers. Adv Mater 10: 161-165.

Liu J, Ma S, Zang L (2013) Preparation and characterization of ammonium-functionalized silica nanoparticle as a new adsorbent to remove Methyl Orange from aqueous solution. Appl Surf Sci 265: 393-398.

Mahmoodi NM, Khorramfar S, Najafi F (2011) Amine-functionalized silica nanoparticle: Preparation, characterization and anionic dye removal ability. Desalination 279: 61-68.

Malamis S, Katsou E (2013) A review on zinc and nickel adsorption on natural and modified zeolite, bentonite and vermiculite: Examination of process parameters, kinetics and isotherms. J Hazard Mater 252: 428-461.

Martínez-Huitle CA, Brillas E (2009) Decontamination of wastewaters containing synthetic organic dyes by electrochemical methods: a general review. Appl Catal B 87: 105-145.

Mckay G, Poots VJ (1980) Kinetics and diffusion processes in colour removal from effluent using wood as an adsorbent. J Chem Technol Biotechnol 30: 279-292.

Messina PV, Schulz PC (2006) Adsorption of reactive dyes on titania-silica mesoporous materials. J Colloid Interface Sci 299: 305-320.

Mohan D, Singh KP (2002) Single and multi-component adsorption of cadmium and zinc using activated carbon derived from bagasse - An agricultural waste. Water Res 36: 2304-2318.

Monash P, Pugazhenthi G (2009) Adsorption of Crystal Violet dye from aqueous solution using mesoporous materials synthesized at room temperature. Adsorption 15: 390-405.

Najafi M, Yousefi Y, Rafati AA (2012) Synthesis, characterization and adsorption studies of several heavy metal ions on amino-functionalized silica nano hollow sphere and silica gel. Sep Purif Technol 85: 193-205.

Nguyen TA, Juang RS (2013) Treatment of waters and wastewaters containing sulfur dyes: a review. Chem Eng J 219: 109-117.

Norhasyimi Rahmat AZA, Abdul Rahman M (2010) A review: Mesoporous Santa Barbara Amorphous-15, Ty pes, Synthesis and its applications towards biorefinery production American. J Appl Sci 12: 1579-1586.

Ogawa M (2002) Photoprocesses in mesoporous silicas prepared by a supramolecular templating approach. J Photochem Photobiol C 3: 129-146.

Órfão JJM, Silva AIM, Pereira JCV, Barata SA, Fonseca IM, Faria PCC, Pereira MFR (2006) Adsorption of a reactive dye on chemically modified activated carbons - Influence of $\mathrm{pH}$. J Colloid Interface Sci 296: 480-489.

Øye G, Glomm WR, Vrålstad T, Volden S, Magnusson H, Stöcker M, Sjöblom J (2006) Synthesis, functionalisation and characterisation of mesoporous materials and sol-gel glasses for applications in catalysis, adsorption and photonics. Adv Colloid Interface Sci 123: 17-32.

Pal N, Bhaumik A (2013) Soft templating strategies for the synthesis of mesoporous materials: Inorganic, organic-inorganic hybrid and purely organic solids. Adv Colloid Interface Sci 189-190: 21-41.

Parab H, Sudersanan M, Shenoy N, Pathare T, Vaze B (2009) Use of agro-industrial wastes for removal of basic dyes from aqueous solutions. Clean Soil Air Water 37: 963-969.

Paul M, Pal N, Bhaumik A (2012) Selective adsorption and release of cationic organic dye molecules on mesoporous borosilicates. Mater Sci Eng C 32: 1461-1468.

Ping Ge FL (2011) kinetics and thermodynamics of heavy metal
$\mathrm{Cu}$ (II) adsorption on mesoporous silaicates. J Environ Stud 20: 339-344.

Plazinski W, Rudzinski W, Plazinska A (2009) Theoretical models of sorption kinetics including a surface reaction mechanism: a review. Adv Colloid Interface Sci 152: 2-13.

Ponnusami V, Gunasekar V, Srivastava SN (2009) Kinetics of Methylene Blue removal from aqueous solution using gulmohar (Delonix regia) plant leaf powder: Multivariate regression analysis. J Hazard Mater 169: 119-127.

Pugazhenthi PMG (2009) Adsorption of Crystal Violet dye from aqueous solution using mesoporous materials synthesized at room temperature. Springer 15: 390-405.

Qin Q, Ma J, Liu K (2009) Adsorption of anionic dyes on ammonium-functionalized MCM-41. J Hazard Mater 162: 133-139.

Qiu H, Lv L, Pan BC, Zhang QJ, Zhang WM, Zhang QX (2009) Critical review in adsorption kinetic models. J Zhejiang University Sci A 10: 716-724.

Qu X, Brame J, Li Q, Alvarez PJ (2012) Nanotechnology for a safe and sustainable water supply: Enabling integrated water treatment and reuse. Accounts Chem Res 46: 834-843.

Qu X, Alvarez PJ, Li Q (2013) Applications of nanotechnology in water and wastewater treatment. Water Res 12: 3931-3946.

Rai HS, Bhattacharyya MS, Singh J, Bansal T, Vats P, Banerjee U (2005) Removal of dyes from the effluent of textile and dye stuff manufacturing industry: a review of emerging techniques with reference to biological treatment. Critical Rev Environ Sci Technol 3: 219-238.

Rajeshwar K, Osugi ME, Chanmanee W, Chenthamarakshan CR, Zanoni MVB, Kajitvichyanukul P, Krishnan-Ayer R (2008) Heterogeneous photocatalytic treatment of organic dyes in air and aqueous media. J Photochem Photobiol C 9: 171-192.

Rehman MSU, Kim I, Han JI (2012) Adsorption of Methylene Blue dye from aqueous solution by sugar extracted spent rice biomass. Carbohydr Polym 90: 1314-1322.

Robinson T, McMullan G, Marchant R, Nigam P (2001) Remediation of dyes in textile effluent: a critical review on current treatment technologies with a proposed alternative. Bioresour Technol 77: 247-255.

Salleh MAM, Mahmoud DK, Karim WAWA, Idris A (2011) Cationic and anionic dye adsorption by agricultural solid wastes: a comprehensive review. Desalination 280: 1-13.

Santos DO, Santos MdLN, Costa JAS, de Jesus RA, Navickiene S, Sussuchi EM, Mesquita ME (2013) Investigating the potential of functionalized MCM-41 on adsorption of Remazol Red dye. Environ Sci Pollut Res 7: 5028-5035.

Saratale RG, Saratale GD, Chang JS, Govindwar SP (2011) Bacterial decolorization and degradation of azo dyes: a review. J Taiwan Inst Chem Eng 42: 138-157.

Shahbazi A, Younesi H, Badiei A (2013) Batch and fixed-bed column adsorption of $\mathrm{Cu}$ (II), $\mathrm{Pb}$ (II) and $\mathrm{Cd}$ (II) from aqueous solution onto functionalised SBA-15 mesoporous silica. Can J Chem Eng 91: 739-750.

Shahbazi A, Younesi H, Badiei A (2014) Functionalized nanostructured silica by tetradentate-amine chelating ligand as efficient heavy metals adsorbent: Applications to industrial effluent treatment. Korean J Chem Eng 9: 1598-1607.

Sharma P, Das MR (2012) Removal of a cationic dye from aqueous solution using graphene oxide nanosheets: Investigation of adsorption parameters. J Chem Eng Data 58: 151-158.

Shreve RN, Watson WN (1922) Dyes classified by intermediates. J Franklin Institute 1: 18-130

Slokar YM, Majcen Le Marechal A (1998) Methods of decoloration of textile wastewaters. Dyes Pigments 37: 335-356. 
Slowing II, Vivero Escoto JL, Wu CW, Lin VSY (2008) Mesoporous silica nanoparticles as controlled release drug delivery and gene transfection carriers. Adv Drug Delivery Reviews 60: $1278-1288$

Sud D, Mahajan G, Kaur MP (2008) Agricultural waste material as potential adsorbent for sequestering heavy metal ions from aqueous solutions - A review. Bioresour Technol 99: 6017-6027.

Taguchi A, Schüth F (2005) Ordered mesoporous materials in catalysis. Micropor Mesopor Mater 77: 1-45.

Tseng HH, Lee WW, Wei MC, Huang BS, Hsieh MC, Cheng PY (2012) Synthesis of $\mathrm{TiO}_{2} / \mathrm{SBA}-15$ photocatalyst for the azo dye decolorization through the polyol method. Chem Eng J 210: 529-538.

Tsoncheva T, Rosenholm J, Linden M, Ivanova L, Minchev C (2007) Iron and copper oxide modified SBA-15 materials as catalysts in methanol decomposition: Effect of copolymer template removal. Appl Catal A 318: 234-243.

Turabik M (2008) Adsorption of basic dyes from single and binary component systems onto bentonite: Simultaneous analysis of Basic Red 46 and Basic Yellow 28 by first order derivative spectrophotometric analysis method. J Hazard Mater 158: $52-64$.

Vidal CB, Barros AL, Moura CP, De Lima ACA, Dias FS, Vasconcellos LCG, Fechine P, Nascimento RF (2011) Adsorption of polycyclic aromatic hydrocarbons from aqueous solutions by modified periodic mesoporous organosilica. J Colloid Interface Sci 357: 466-473.

Vigo TL (1994) Textile processing and properties: preparation, dyeing, finishing, and performance. Elsevier Science Publishers BV.

Vimonses V (2011) Development of multifunctional nanomaterials and adsorption-photocatalysis hybrid system for wastewater reclamation. $\mathrm{PhD}$ Thesis, Adelaide University, Australia.

Vinu A, Hossain KZ, Ariga K (2005) Recent Advances in Functionalization of Mesoporous Silica. J Nanosci Nanotechnol 5: 347-371.

Walcarius A, Mercier L (2010) Mesoporous organosilica adsorbents: Nanoengineered materials for removal of organic and inorganic pollutants. J Mater Chem 20: 4478-4511.

Wang S, Li H (2006) Structure directed reversible adsorption of organic dye on mesoporous silica in aqueous solution. Micropor Mesopor Mater 97: 21-26.

Weng CH, Lin YT, Tzeng TW (2009) Removal of Methylene Blue from aqueous solution by Yaadsorption onto pineapple leaf powder. J Hazard Mater 170: 417-424.

Wu G, Koliadima A, Her Y, Matijević S (1997) Adsorption of dyes on nano size modified silica particles. J Colloid Interface Sci 195: 222-228.

Wu X, Hui KN, Hui KS, Lee SK, Zhou W, Chen R, Hwang DH, Cho YR, Son YG (2012) Adsorption of Basic Yellow 87 from aqueous solution onto two different mesoporous adsorbents. Chem Eng J 180: 91-98.

Yadla SV, Sridevi V, Lakshmi MC (2012) A review on adsorption of heavy metals from aqueous solution. J Chem Biological Physical Sci 2: 1585-1593.

Yan H, Li H, Yang H, Li A, Cheng R (2013) Removal of various cationic dyes from aqueous solutions using a kind of fully biodegradable magnetic composite microsphere. Chem Eng J 223: 402-411.

Yan Z, Li G, Mu L, Tao S (2006a) Pyridine-functionalized mesoporous silica as an efficient adsorbent for the removal of acid dyestuffs. J Mater Chem 16: 1717-1725.

Yan Z, Tao S, Yin J, Li G (2006b) Mesoporous silicas functionalized with a high density of carboxylate groups as efficient absorbents for the removal of basic dyestuffs. J Mater Chem 16: 2347-2353.

Yang H, Feng Q (2010a) Characterization of pore-expanded amino-functionalized mesoporous silicas directly synthesized with dimethyldecylamine and its application for decolorization of sulphonated azo dyes. J Hazard Mater 180: 106-114.

Yang H, Feng Q (2010b) Direct synthesis of pore-expanded amino-functionalized mesoporous silicas with dimethyldecylamine and the effect of expander dosage on their characterization and decolorization of sulphonated azo dyes. Micropor Mesopor Mater 135: 124-130.

Ying JY, Mehnert CP, Wong MS (1999) Synthesis and applications of supramolecular-templated mesoporous materials. Angew Chem Int Ed 38: 56-77.

Yokoi T, Kubota Y, Tatsumi T (2012) Amino-functionalized mesoporous silica as base catalyst and adsorbent. Appl Catal 421-422: 14-37.

Zhang PLL (2007) Adsorption of dyes from aqueous solutions or suspensions with clay nano-adsorbents. Sep Purif Technol 58: 32-39.

Zhao L, Qin H, Wu Ra, Zou H (2012) Recent advances of mesoporous materials in sample preparation. J Chromatogr A 1228: 193-204.

Zhuang X, Wan Y, Feng C, Shen Y, Zhao D (2009) Highly efficient adsorption of bulky dye molecules in wastewater on ordered mesoporous carbons. Chem Mater 21: 706-716.

Zubieta C, Sierra MB, Morini MA, Schulz PC, Albertengo L, Rodríguez MS (2008) The adsorption of dyes used in the textile industry on mesoporous materials. Colloid Polym Sci 286: 377-384. 